\title{
A Peek at PEEP in Patients With AIDS
}

PEEP was described to improve oxygenation in ventilated patients with ARDS in 1967, ${ }^{1}$ although the mechanism of action was not clear. The potential benefits of lung volume recruitment maneuvers became apparent from results of a randomized controlled trial of mechanical ventilation of patients with ARDS in 1998. ${ }^{2}$ Since that time there has been a proliferation of literature in the area of lung volume recruitment. ${ }^{3}$ It has become recognized that PEEP largely acts to maintain the recruitment benefit achieved by tidal ventilation. More complex maneuvers have been studied over the past decade to open atelectatic lung units, such as sustained inflation, ${ }^{4}$ incremental PEEP, ${ }^{5}$ intermittent higher volume ventilation or "sighs," 6 and highfrequency oscillation. ${ }^{7}$ In this context, the physiological study by Anjos et al published in this issue of RESPIRATORY $\mathrm{CARE}^{8}{ }^{8}$ evaluating the oxygenation benefits of PEEP, is somewhat anachronistic (although carried out in 2000), but addresses some important physiological principles and demonstrates the complexities of lung volume physiology.

See the Original Study on Page 211

In their short-term physiologic study, Anjos et al assessed the effects of 3 levels of PEEP $\left(5,10\right.$, and $\left.15 \mathrm{~cm} \mathrm{H}_{2} \mathrm{O}\right)$ with $5 \mathrm{~cm} \mathrm{H}_{2} \mathrm{O}$ pressure support, in 30 patients with the acquired immunodeficiency syndrome (AIDS) presenting with acute hypoxemia, primarily due to respiratory infections. While oxygenation improved with increasing PEEP, the improvement varied depending on the sequence of application of PEEP. Further, when compared with baseline settings ( 0 PEEP and 0 pressure support), the oxygenation improvement was significant only with PEEP $5 \mathrm{~cm} \mathrm{H}_{2} \mathrm{O}$, and not at higher levels of PEEP. When PEEP $15 \mathrm{~cm} \mathrm{H}_{2} \mathrm{O}$ was applied, the improvement in oxygenation was significant compared only with 0 PEEP (with pressure support of $5 \mathrm{~cm} \mathrm{H}_{2} \mathrm{O}$ ). The investigators observed elevation in $\mathrm{P}_{\mathrm{aCO}_{2}}$ as PEEP was increased, especially with the highest level of PEEP. The addition of $5 \mathrm{~cm} \mathrm{H}_{2} \mathrm{O}$ pressure support with no PEEP was associated with reductions in respiratory rate and dyspnea. The authors conclude that progressive elevations of PEEP in AIDS patients with hypoxemic respiratory failure improve oxygenation, and the addition of pressure support promotes further subjective improvement. These results are not surprising, and should be generalizable to non-AIDS patients, given that more than $50 \%$ of their patients had community-acquired pneumonia, which should have a similar physiological response to PEEP regardless of human immunodeficiency virus infection.

The study was well done: the methods are well described, and the design is rigorous. However, there are a few limitations of this physiological trial. The application of $\mathrm{F}_{\mathrm{IO}_{2}}$ of 1 , even for brief periods, is associated with reabsorption atelectasis ${ }^{9}$; in this trial, this may have reduced the degree of PEEP-induced recruitment and improvement in oxygenation. Another limitation, acknowledged by the investigators, is the short washout period, which may have been insufficient to return to baseline conditions between PEEP exposures. A further limitation is that Anjos and his colleagues used an intensive care ventilator to deliver noninvasive ventilation. As intensive care ventilators do not generally compensate for mask leaks, it is possible that the use of higher applied PEEP may have been associated with greater leak, and thus may not have translated to higher alveolar PEEP, thus the lack of additional oxygenation benefit. Finally, the authors conclude that the recruitment response to PEEP was similar regardless of etiology of respiratory failure; however, the subgroups of patients with tuberculosis and fungal pneumonia (including Pneumocystis jiroveci pneumonia) are too small to draw any useful conclusions.

This study is complex to interpret and raises some interesting physiological concepts. In this study the major symptomatic benefit was associated with the addition of $5 \mathrm{~cm} \mathrm{H}_{2} \mathrm{O}$ pressure support, even in the absence of PEEP, likely due to an effect on work of breathing. Increasing PEEP levels had a relatively small effect on oxygenation and no effect on subjective dyspnea. This may be due to the fact that the major recruitment effect is attributable to tidal ventilation, and PEEP merely prevents loss of this tidal recruitment. ${ }^{10}$ Higher PEEP levels may also have complex effects that may be difficult to anticipate. The effects on individual alveolar clusters is heterogeneous, dependent on the size of the alveoli, the degree of injury, and the characteristics of adjacent alveoli. ${ }^{11,12}$ This may result in overdistention of certain alveoli, even on exposure to peak pressures generally considered acceptable. Overdistention would reduce alveolar perfusion and increase dead space, therefore potentially affecting both oxygen and carbon dioxide levels. The study is also affected by the time-dependence of recruitment and the volume 


\section{A Peek at PeEP in Patients With AIDS}

history of the lung. Prior peak inspiratory pressure will have an effect on the pressure-volume relationship ${ }^{13}$ and therefore the recruitment occurring at a particular PEEP level. This is demonstrated by the fact that a progressive improvement in oxygenation was seen only in the subgroup with an initial PEEP of $5 \mathrm{~cm} \mathrm{H}_{2} \mathrm{O}$, and not in those who initially received 10 or $15 \mathrm{~cm} \mathrm{H}_{2} \mathrm{O}$ in the randomly applied intervention. The washout period of $20 \mathrm{~min}$ may have been insufficient to return the lung to its baseline characteristics.

How does this study help clinicians? Clinicians cannot conclude from this trial that noninvasive pressure support/ PEEP is associated with longer-term clinical benefit, as the study was not designed to evaluate clinical outcomes such as avoidance of intubation; and the study included a heterogeneous group of patients. However, the conclusions that are relevant to bedside clinicians are that pressure support of $5 \mathrm{~cm} \mathrm{H}_{2} \mathrm{O}$, regardless of PEEP, was associated with a reduction in respiratory rate and dyspnea, and that high PEEP should be used cautiously, given that PEEP higher than $10 \mathrm{~cm} \mathrm{H}_{2} \mathrm{O}$ may not be associated with improvements in oxygenation, and may be associated with elevations in $\mathrm{P}_{\mathrm{aCO}}$.

\section{Sangeeta Mehta MD FRCP(C) Stephen E Lapinsky MB BCh FRCP(C)}

Intensive Care Unit Mount Sinai Hospital

and

Interdepartmental Division of Critical Care Medicine University of Toronto Toronto, Ontario, Canada

The authors have disclosed no conflicts of interest.

Correspondence: Sangeeta Mehta MD, Mount Sinai Hospital, 600 University Avenue, 18-216, Toronto, Ontario M5G 1X5, Canada. E-mail: geeta.mehta@utoronto.ca.

DOI: $10.4187 /$ respcare. 01726

\section{REFERENCES}

1. Ashbaugh DG, Bigelow DB, Petty TL, Levine BE. Acute respiratory distress in adults. Lancet 1967;2(7511):319-323.

2. Amato MB, Barbas CS, Medeiros DM, Magaldi RB, Schettino GP, Lorenzi-Filho G, et al. Effect of a protective-ventilation strategy on mortality in the acute respiratory distress syndrome. N Engl J Med 1998;338(6):347-354.

3. Fan E, Wilcox ME, Brower RG, Stewart TE, Mehta S, Lapinsky SE, Meade MO, Ferguson ND. Recruitment maneuvers for acute lung injury: a systematic review. Am J Respir Crit Care Med 2008;178(11): 1156-1163.

4. Lapinsky SE, Aubin M, Mehta S, Boiteau P, Slutsky AS. Safety and efficacy of a sustained inflation for alveolar recruitment in adults with respiratory failure. Intensive Care Med 1999;25(11):1297-1301.

5. Borges JB, Okamoto VN, Matos GF, Caramez MP, Arantes PR, Barros F, et al. Reversibility of lung collapse and hypoxemia in early acute respiratory distress syndrome. Am J Respir Crit Care Med 2006;174(3):268-278.

6. Lim CM, Koh Y, Park W, Chin JY, Shim TS, Lee SD, et al. Mechanistic scheme and effect of "extended sigh" as a recruitment maneuver in patients with acute respiratory distress syndrome: a preliminary study. Crit Care Med 2001;29(6):1255-1260.

7. Ferguson ND, Chiche JD, Kacmarek RM, Hallett DC, Mehta S, Findlay GP, et al. Combining high-frequency oscillatory ventilation and recruitment maneuvers in adults with early acute respiratory distress syndrome: the Treatment with Oscillation and an Open Lung Strategy (TOOLS) Trial pilot study. Crit Care Med 2005;33(3):479486.

8. Anjos CFD, Schettino GPP, Park M, Souza VS, Neto AS. A randomized trial of noninvasive positive end expiratory pressure in patients with acquired immune deficiency syndrome and hypoxemic respiratory failure. Respir Care 2012;57(2):211-220.

9. Santos C, Ferrer M, Roca J, Torres A, Hernández C, RodriguezRoisin R. Pulmonary gas exchange response to oxygen breathing in acute lung injury. Am J Respir Crit Care Med 2000;161(1):26-31.

10. Cereda M, Foti G, Musch G, Sparacino ME, Pesenti A. Positive end-expiratory pressure prevents the loss of respiratory compliance during low tidal volume ventilation in acute lung injury patients. Chest 1996;109(2):480-485.

11. Schirrmann K, Mertens M, Kertzscher U, Kuebler WM, Affeld K. Theoretical modeling of the interaction between alveoli during inflation and deflation in normal and diseased lungs. J Biomech 2010 19;43(6):1202-1207.

12. Mertens M, Tabuchi A, Meissner S, Krueger A, Schirrmann K, Kertzscher U, et al. Alveolar dynamics in acute lung injury: heterogeneous distension rather than cyclic opening and collapse. Crit Care Med 2009;37(9):2604-2611.

13. Takeuchi M, Sedeek KA, Schettino GP, Suchodolski K, Kacmarek RM. Peak pressure during volume history and pressure-volume curve measurement affects analysis. Am J Respir Crit Care Med 2001; 164(7):1225-1233. 